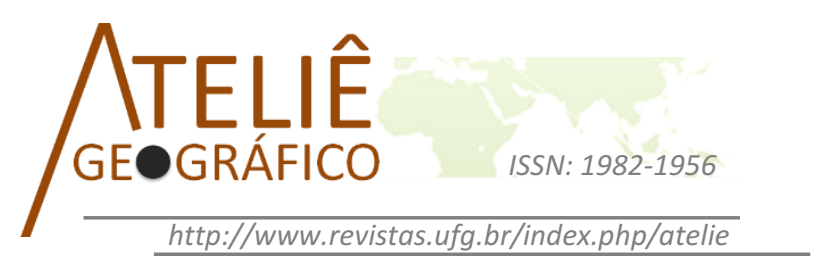

\title{
Análise da diferença entre dados altimétricos em uma bacia hidrográfica através da comparação entre modelos digitais de elevação
}

\author{
Analysis of difference altimetric data in a hydrographic basin \\ through comparison between digital models elevation \\ Analyse de la différence entre les données altimétriques dans \\ un bassin hydrographique à travers la comparaison entre les \\ modèles numériques d'élévation
}

Adalto Moreira Braz

Universidade Federal de Goiás

adaltobraz.geografia@gmail.com

Fernanda Vieira Xavier

Universidade do Estado de Mato Grosso

ferx.unesp@gmail.com

Patricia Helena Mirandola Garcia

Universidade Federal de Mato Grosso do Sul

patricia.garcia@ufms.br

\begin{abstract}
Resumo
A utilização de Modelos Digitais de Elevação (MDE) obtidos por sensores orbitais representa uma alternativa para suprir a carência de mapeamentos nos mais diversificados segmentos de estudos. Sobre a possibilidade de estudar o relevo, um fator importante que favoreceu a inclusão do mesmo na identificação e na análise de sistemas terrestres advém de recentes coletas de dados topográficos por técnicas de sensoriamento remoto. Os dados topográficos da bacia hidrográfica do córrego Ribeirãozinho (BHCR) foram espacializados objetivando identificar diferenças dos dados altimétricos e analisar a qualidade dos mesmos, provenientes de imagens SRTM (banda C e X), Topodata e ASTER GDEM. Através da aplicação do geoprocessamento e análise estatística, utilizou-se do teste de Tukey, que consistiu em comparar e definir a menor diferença significativa entre os valores, avaliando a diferença de topografia do terreno gerado a partir do uso de um dos MDEs distribuídos gratuitamente. Além disso, buscou-se apontar o melhor instrumento para aplicações correlatas à proposta aqui apresentada.
\end{abstract}

Palavras-chave: SRTM, TOPODATA, ASTER GDEM, Teste de Tukey. 


\begin{abstract}
The utilization of Digital Elevation Models (DEM) got from orbitals sensors is an alternative to overcome the mapping deficiency in the most diverse segments of studies. On the possibility to relief study, an important factor that favored the inclusion of the same in the identification and terrestrial systems analysis comes from recent topographic data collected by remote sensing techniques. Topographic data of the Ribeirãozinho hydrographic basin stream (RHBS) were spatialized aiming at identifying differences in altimetry data and analyze their quality, from SRTM images (C and X band), TOPODATA and ASTER GDEM. Through the application of geoprocessing and statistic analysisit was used Tukey test, which consisted on comparing and define the smallest significant difference between values, evaluating the difference in topography of the terrain generated from the use of one of the DEM distributed free of charge. Besides that, sought to point out the best instrument for applications related to the proposal presented here.
\end{abstract}

Keywords: SRTM, TOPODATA, ASTER GDEM, Tukey test.

\begin{abstract}
Résumé
L'utilisation de Modèles Numériques d'Élévation (MNE) obtenus grâce à des capteurs orbitaux représente une alternative pour répondre aux insuffisances cartographiques dans la diversité des éléments des études. Sur la possibilité d'étudier le relief, un facteur important qui favorise l'inclusion de celui-ci dans l'identification et l'analyse des systèmes terrestres provenant de la récente collecte de données topographiques par des techniques de géotraitement. Les données topographiques du bassin hydrographique du cours d'eau Ribeirãozinho (BHCR) ont été spatialisés dans l'objectif d'identifier des données altimétriques et d'analyser leur qualité, provenant des images SRTM (bande C et X), Topodata et ASTER GDEM. À travers l'application du géotraitement et de l'analyse statistique, a été utilisé le test de Tukey, qui consiste à comparer et définir la plus faible différence significative entre les valeurs, l'évaluation de la différence de la topographie générée à partir de l'utilisation de l'un des protocoles d'accord distribué gratuitement. De plus, on cherche à identifier le meilleur instrument pour les applications liées à la présente proposition.
\end{abstract}

Mots-clés: SRTM, Topodata, ASTER GDEM, Test de Tukey.

\title{
Introdução
}

Nas últimas décadas, usuários de geotecnologias, têm vivenciado uma crescente aplicação principalmente do sensoriamento remoto e geoprocessamento a partir de métodos de espacialização e quantificação de dados utilizados para representações cartográficas e obtenção de informações gratuitas que tem auxiliado, dentre outros estudos, nos de cunho ambiental. Tais informações têm sido usadas amplamente em estudos técnicos e científicos contribuintes nas áreas ambientais como zoneamentos, análises ambientais, estudos ambientais em bacias hidrográficas, entre outros, amparando decisões aplicadas em planejamento ambiental.

Especificamente sobre a possibilidade de estudar o relevo, um fator importante na identificação e na análise de sistemas terrestres advém de recentes coletas de dados topográficos por técnicas de sensoriamento remoto. A utilização de Modelos Digitais de 
Elevação (MDE) obtidos por sensores orbitais representa uma alternativa de grande interesse para suprir a carência de mapeamentos nos mais diversificados segmentos de estudos (VALERIANO, 2005). Um MDE é definido como uma

criação de representações de superfícies física ou artificialmente criadas, através de processos matemáticos, ou seja, através da modelagem procura-se determinar a superfície que melhor representa um conjunto de dados pontuais, em geral, por ajuste de funções ou por interpolações (SIMÕES, 1993, p. 30).

A mesma autora ressalta a diversidade entre termos utilizados para uma mesma finalidade, afirmando que na literatura encontram-se diversos sinônimos para a modelagem digital do terreno. Dentre os mais comuns estão Modelo Numérico de Terreno (MNT), Modelo Numérico de Elevação (MNE), Modelo Digital de Elevação (MDE), Digital Terrain Model (DTM), Digital Elevation Model (DEM) (SIMÕES, 1993) e mais recente surgem os Modelos Digitais de Superfície (MDS).

Atualmente, a principal diferença percebida está entre o MDE e o MDS. Sendo um MDE representado por cotas do terreno e um MDS representado por cotas de elementos que estão acima (na superfície) do terreno, como vegetação e infraestruturas. Portanto o MDE representa a elevação (altimetria) do terreno, enquanto o MDS representa a elevação dos elementos contidos acima do terreno representado.

Enquanto representação digital e a possibilidade de tratamento em Sistemas de Informações Geográficas (SIG), entende-se por MDE arquivos que contêm registros altimétricos estruturados em linhas e colunas georreferenciadas, como uma imagem com um valor de elevação em cada pixel. Os registros altimétricos devem ser valores de altitude do relevo, idealmente, para que o MDE seja uma representação da topografia (VALERIANO, 2008).

Os MDEs são fontes fundamentais para extração de informações do relevo em grandes áreas ou de difícil acesso. A partir de dados de elevação são extraídas medidas morfométricas como declividade e aspecto do terreno, que por sua vez podem ser empregadas em uma diversidade de estudos, como em modelos de erosão laminar do solo, modelos meteorológicos, riscos de escorregamento em encostas, mapas de aptidão agrícola, extração de feições geológicas, na caracterização de estruturas florestais dentre outros exemplos (IWASHITA e SOUZA-FILHO, 2009).

Os Modelos Digitais de Elevação (MDE) são representações de dados topográficos passíveis de tratamento em Sistemas de Informações Geográficas (SIG). O processamento destes dados em SIG permite a caracterização do estado e de processos do sistema terrestre em abordagem especializada (VALERIANO e ROSSETTI, 2010, p. 19). 
Através da aplicação do geoprocessamento e análises estatísticas, pretendeu-se espacializar cartograficamente dados topográficos da bacia hidrográfica do córrego Ribeirãozinho (BHCR) e comparar produtos gerados a partir de imagens de diferentes instrumentos (SRTM, Topodata, ASTER), como curvas de nível, Modelo Digital de Elevação (MDE) e hipsometria da área estudada.

A área amostral escolhida foi a bacia hidrográfica do córrego Ribeirãozinho, localizada no município de Silvíria/MS, entre as coordenadas $20^{\circ} 23^{\prime} 48^{\prime \prime} \mathrm{S}, 52^{\circ} 3^{\prime} 16^{\prime \prime}$ $\mathrm{W} ; 20^{\circ} 19^{\prime} 14^{\prime \prime} \mathrm{S}, 51^{\circ} 57^{\prime} 8^{\prime \prime} \mathrm{W}$ (sistema de coordenadas geográficas, datum SIRGAS 2000), com extensão de 3.144 ha $\left(31,44 \mathrm{Km}^{2}\right)$.

A bacia hidrográfica está inserida em sua maior parte numa região de relevo plano e suave ondulado em algumas localizações. Sua amplitude altimétrica é de apenas $146 \mathrm{~m}$ variando de $419 \mathrm{~m}$ em seu ponto mais alto a $273 \mathrm{~m}$ nos locais mais baixos. Apresenta declives de no máximo $13^{\circ}$, aproximadamente, porém em sua maior parte, a declividade no terreno concentra-se em inclinações de até $4,5^{\circ}$. Pode-se classificar, de acordo com o IBGE (2009), que as formas do terreno da bacia do Ribeirãozinho são planas a suave onduladas. No alto curso as inclinações são de até $2,6^{\circ} \mathrm{em}$ alguns locais, que se apresentam em terrenos mais aplainados. Já no médio e em parte do baixo curso, as inclinações se concentram em até $4,5^{\circ}$, apresentando uma configuração suave ondulado do terreno. Vale ressaltar que essa dinâmica ocorre em alguns pontos isolados, sendo usada como exemplo os valores mais baixos e mais altos de declividade na bacia hidrográfica. $\mathrm{O}$ que caracteriza uma topografia relevante para a análise comparativa entre os pontos amostrais da altimetria, sendo uma área que não possui desníveis topográficos ou maiores amplitudes altimétricas, poucas áreas de vegetação de grande porte (que pudesse interferir nos sinais de RADAR) e relativa homogeneidade quanto ao relevo (plano), se comparado com outras localidades do Estado de Mato Grosso do Sul.

É importante elucidar que o presente trabalho não objetivou estudar o desenvolvimento técnico, processo de aquisição e processamento avançado das imagens de RADAR (Radio Detection and Ranging) aqui mencionadas. Deste modo, pretendeuse então, fazer uma análise comparativa da diferença dos dados altimétricos (de livre acesso) e sua viabilidade de aplicação em estudos ambientais, principalmente envolvendo bacias hidrográficas.

Através da aplicação de um teste de comparação múltipla adotado para a análise da diferença estatística entre os valores altimétricos de cada instrumento, usou-se do teste de Tukey objetivando identificar as diferenças dos valores altimétricos, provenientes de imagens de RADAR e ópticas, como SRTM (Shuttle Radar Topography Mission - banda C e banda X), Topodata e ASTER (Advanced Spaceborne Thermal Emission and Reflection Radiometer) GDEM (Global Digital Elevation Model). Além disso, buscou-se apontar o melhor instrumento, de distribuição gratuita, para aplicações correlatas às propostas de estudos ambientais em bacias hidrográficas. 


\section{Referencial Teórico}

\section{Shuttle Radar Topography Mission (SRTM)}

Shuttle Radar Topography Mission (SRTM), nome dado à missão de imageamento global da superfície terrestre por RADAR. As instituições dos Estudos Unidos da América responsáveis pela missão foram a Aeronautics and Space Administration (NASA) e a National Geospatial-Intelligence Agency (NGA). E a agência espacial da Alemanha, a Deutsches Zentrum für Luft- und Raumfahrt e.V. (DLR), além da agência espacial da Itália, a Agenzia Spaziale Italiana (ASI). A missão colocou em órbita em fevereiro de 2000 a nave espacial Endeavour levando um sistema de RADAR modificado e os dados da missão foram coletados durante 11 dias (de 11 a 22 de fevereiro). A missão percorreu 16 órbitas por dia e ao final totalizaram-se 176 órbitas percorridas. A missão SRTM foi concluída com a coleta de $12 \mathrm{~Tb}$ de dados que foram processados para a formação dos Modelos Digitais de Elevação (VALERIANO, 2004; BRAZ e MIRANDOLA, 2014).

A missão SRTM foi planejada de modo que coletasse medidas tridimensionais da superfície terrestre através de técnicas de interferometria. Para isso foram necessárias duas antenas, sendo uma principal a bordo da nave e uma antena externa, na extremidade do mastro de $60 \mathrm{~m}$, sendo estas antenas uma para a banda $\mathrm{C}$ e outra para a banda $\mathrm{X}$ (VALERIANO, 2004; JPL, 2015). A interferometria é um conjunto de técnicas e o estudo dos padrões de interferência criados por sinais de RADAR e recebidos pela combinação de duas antenas diferentes.

O principal exemplo de InSAR (Interferometric Sinthetic Aperture Radar) configurado para maximizar a aquisição de dados interferométricos é o do sistema utilizado na missão SRTM. Esta missão foi a primeira vez em que se utilizou um sistema SAR (Sinthetic Aperture Radar) com duas antenas (única passagem) em órbita. Para mapear toda a superfície da Terra, foram realizadas 159 órbitas, cujos dados foram armazenados a bordo do ônibus espacial, uma vez que o volume de dados produzidos pelo sistema excedia à capacidade do sistema de transmissão do ônibus espacial (NOVO, 2010, p. 126).

De acordo com Rosa (2009), o princípio básico de operação de um RADAR ativo é a emissão de um sinal de rádio, sendo este sinal refletido por um objeto distante, retornando ao sensor onde este sinal é processado e extraído o tempo decorrido entre a emissão e a recepção e processado

O sistema de RADAR baseia-se no fato de que a radiação eletromagnética na região de micro-ondas propaga-se através de um meio até atingir a Terra. Quando isso ocorre, parte desta radiação pode ser refletida de volta para o sistema e registrada. A radiação refletida pela superfície depende basicamente da 
rugosidade superficial do terreno e da geometria da superfície do terreno em relação à irradiância (ROSA, 2009, p. 86-87).

Na missão SRTM foi utilizada a interferometria de base fixa. Isto significa que dois conjuntos de dados do instrumento de RADAR foram recolhidas ao mesmo tempo e com uma distância fixa entre as antenas. Durante a missão, a antena principal a bordo do ônibus espacial recolhia um conjunto de dados e este mesmo conjunto de dados também era coletado pela antena externo localizado na extremidade do mastro (JPL, 2015).

A antena principal, localizada no compartimento de carga da nave emitiu na superfície terrestre pulsos de ondas de RADAR. Quando as ondas de RADAR atingiam a superfície, os raios eram espalhados em várias direções e estas ondas espalhadas foram coletadas pelas duas antenas SRTM (JPL, 2015).

O processamento dos dados coletados visou à formação de um MDE mundial, elaborado continente por continente, iniciado com a América do Norte. Conforme a coleta de dados foi concluída em cada continente, seguiu-se o envio destes dados ao National Imagery and Mapping Agency (NIMA), onde foram editados, verificados e ajustados aos padrões norte-americanos de exatidão de mapas (National Map Accuracy Standards). Estes dados, eram então devolvidos à NASA para distribuição pública através do USGS (United States Geological Survey) (VALERIANO, 2004).

Os dados da banda $\mathrm{C}$ foram processados no JPL/NASA e os dados da banda $\mathrm{X}$ no DLR, estes são usados para criar MDE de resolução mais alta $(30 \mathrm{~m})$, porém, à época, sem cobertura global (VALERIANO, 2004; JPL, 2015).

Em janeiro de 2002, a NASA iniciou a distribuição pública de pequenos conjuntos de dados SRTM de locais dentro dos Estados Unidos. Foram gerados MDE sob resolução de 30m (a rigor, em coordenadas geográficas, como 1 arco-segundo) para os Estados Unidos e planejados sob $90 \mathrm{~m}$ (3 arco-segundo) para o resto do mundo (VALERIANO, 2004).

Os dados SRTM, na forma em que foram disponibilizados inicialmente para a América do Sul apresentavam resolução espacial de 3 arco-segundos ( $(90 \mathrm{~m})$ e resolução vertical de $1 \mathrm{~m}$. Toda a aquisição dos dados SRTM foi planejada a suprir mapeamentos em escalas entre 1:100.000 e 1:250.000 (VALERIANO, 2008).

As peculiaridades indesejáveis do modelo SRTM dizem respeito à sua sensibilidade a quaisquer objetos presentes sobre a superfície do terreno, tais como antenas, edificações e mesmo variações da cobertura vegetal, já que sua inclusão no modelo atrapalha a percepção da superfície do terreno em si, além receber interferência nos dados altimétricos pelo dossel de florestas. Porém, esse efeito não é constante nos dados e dependem da época do sobrevoo e das condições da cobertura vegetal (VALERIANO, 2004; VALERIANO, 2008). 


\section{Banda $C$}

Radares banda $\mathrm{C}$ tem uma frequência de aproximadamente $5.3 \times 109$ ciclos $/$ seg. (5 GHz) $(\lambda=5.7 \mathrm{~cm})$ (SOARES, 2005). O RADAR (antena) de banda C, possui polarizações $\mathrm{HH}$ e VV, transmitia e recebia sinais (ondas) de RADAR com $5,6 \mathrm{~cm}$ de comprimento (figura 01). Devido sua resolução espacial ser menor, cobre trechos mais largos da superfície terrestre, com $225 \mathrm{~km}$ de largura por cena imageada em cada órbita (SOUZA-FILHO, 2003; JPL, 2015).

Os procedimentos aconteceram da seguinte forma: (1) processamento sistemático dos dados globais continente por continente, na resolução de 1" x 1" lat/long ( $\sim 30$ x 30m); (2) reamostragem dos dados na resolução de 3" x 3" lat/long ( $90 \times 90 \mathrm{~m})$; (3) reamostragem dos dados na resolução 30 " x 30" lat/long ( $900 \times 900 \mathrm{~m})$, com a geração do produto denominado SRTM30. A parte principal do processamento dos dados do RADAR de banda $\mathrm{C}$ durou cerca de dois anos.

\begin{tabular}{|l|l|}
\hline \multicolumn{2}{|c|}{ Características dos MDEs primários do SRTM RADAR Banda-C } \\
\hline Acurácia Horizontal & ${ }^{*} 20$ metros \\
\hline Acurácia Vertical & ${ }^{*} 4$ metros \\
\hline Amostragem Horizontal & $* * 1^{*} \times 1^{*}$ lat/long $(30 \times 30 \mathrm{~m})$ \\
\hline Amostragem Vertical & 1 metro \\
\hline Projeção & $\begin{array}{l}\text { Coordenadas geográficas } \\
\text { (latitude/longitude) }\end{array}$ \\
\hline Esferóide & WHS 84 \\
\hline Formato dos dados & 16 bits (signed integer) \\
\hline \multicolumn{2}{|c|}{${ }^{*}$ acurácia para $66 \%$ dos dados (restante 10-16m) } \\
\hline${ }^{* *}$ aproximadamente $30 \mathrm{~m}$ para latitudes médias/Equador
\end{tabular}

Figura 01. Características dos MDEs primários do SRTM RADAR banda $C$.

Fonte: Disponível em: <http://mundogeo.com/blog/2003/12/18/o-relevodas-americas-como-nunca-antes-visto/>.

\section{Banda X}

Radares banda $X$ tem uma frequência de aproximadamente $9.3 \times 109$ ciclos $/$ seg. $(9 \mathrm{GHz})(\lambda=3.2 \mathrm{~cm})$ (SOARES, 2005). Nos radares da banda $\mathrm{X}$, as imagens são mais detalhadas e os contornos são mais bem delineados que nos radares da banda $\mathrm{C}$ $(5,6 \mathrm{~cm})$. Porém o alcance do sinal da banda $\mathrm{X}$ é menor e mais afetados por fenômenos atmosféricos e meteorológicos, que diminuem a qualidade da imagem final, podendo até mascarar alguns detalhes do terreno.

O RADAR de banda X, possuía um único feixe de polarização VV, transmitia e recebia sinais (ondas) de RADAR com $3 \mathrm{~cm}$ de comprimento. Cobriu faixas menores, de $50 \mathrm{~km}$ de largura, porém não teve cobertura global de forma contínua (SOUZA-FILHO, 2003; JPL, 2015). 
Em 23 de setembro de 2014, a Casa Branca anunciou a disponibilidade pública dos dados topográficos de maior resolução e que estes seriam lançados mundialmente durante o próximo ano (2015). O primeiro lançamento dos dados da banda $\mathrm{X}$ aconteceu já em novembro de 2014, e incluiu toda a América do Sul e América do Norte, grande parte da Europa, e ilhas do leste do Oceano Pacífico (PRATES, 2014; JPL, 2015).

Com o anúncio feito e processamento em andamento, os dados foram/estão sendo disponibilizados pelo United States Geological Survey (USGS), a partir da plataforma Earth Explorer

\section{Topodata}

A iniciativa TOPODATA propõe que derivações básicas da informação topográfica (MDE, declividade, orientação de vertentes, curvaturas etc.), a partir de dados SRTM (banca C), para que estes dados estejam prontamente à disposição da comunidade para seu uso (VALERIANO e ROSSETTI, 2010). No intuito de se acelerar este processo, a iniciativa TOPODATA foi conduzida na forma de projeto para o cálculo e a oferta de variáveis geomorfométricas locais com estes dados por todo o território nacional. Tais variáveis correspondem aos elementos básicos sobre os quais se fundamentam as técnicas de interpretação e análise do relevo (VALERIANO, 2008).

Dos produtos gerados e oferecidos pelo TOPODATA, talvez o mais difundido e de maior uso pela comunidade seria o MDE, conforme Valeriano e Rossetti (2010), foram gerados a partir de um refinamento da resolução dos dados originais da SRTM banda C.

Tal refinamento de resolução foi feito mediante um processo de interpolação, em que se calculam valores de células (pixels) intermediários aos valores de entrada. Os cálculos e interpolações foram programadas em forma de lote (macro) no ambiente do software Surfer, tais processos são exemplificados na figura 02 (VALERIANO e ALBUQUERQUE, 2010; VALERIANO e ROSSETTI, 2010).

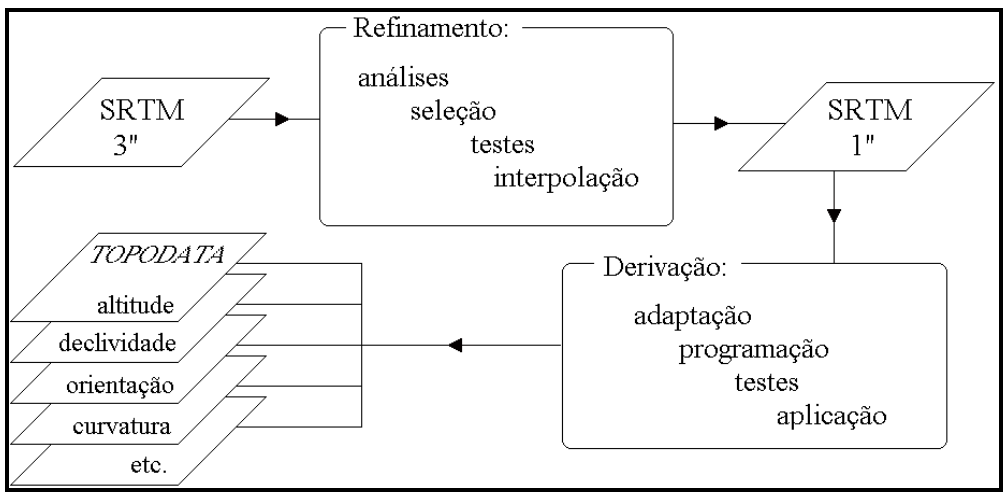

Figura 02. Processamento dos dados SRTM para a construção do TOPODATA. 
Fonte: Valeriano e Albuquerque (2010).

Os dados TOPODATA estão todos estruturados em quadrículas compatíveis com a articulação $1: 250.000$, portanto, em folhas de $1^{\circ}$ de latitude por $1,5^{\circ}$ de longitude (TOPODATA, 2015). Especificamente quanto aos MDEs estes são disponibilizados em formato de grid ( $g r d$ ), ou seja, os arquivos possuem informações $X Y Z$ e têm margens de 30 linhas/colunas, equivalentes a $0,025^{\circ}$ ou $1,5^{\prime}$. São disponibilizados em formato GeoTIFF (.tiff), referenciados em latitude/longitude (sem projeção), com coordenadas geográficas em graus decimais e datum WGS 1984 (VALERIANO, 2008; TOPODATA, 2015).

\section{Advanced Spacerbone Thermal Emission and Reflection Radiometer - Global Digital Elevation Model (ASTER GDEM)}

$\mathrm{O}$ instrumento ASTER (Advanced Spaceborne Thermal Emission and Reflection Radiometer) foi construído no Japão e lançado a bordo do satélite Terra (EOS SER-2), em uma parceria do Ministério da Economia, Comércio e Indústria (METI) do Japão e da Administração Nacional da Aeronáutica e do Espaço (NASA) dos Estados Unidos da América, em 29 de junho de 2009, permanecendo em funcionamento desde a data de seu lançamento. Para a obtenção dos dados de elevação (MDE), o instrumento opera no modo estereoscópico, com as bandas 3N (nadir) e 3B (backward), correspondentes à faixa do infravermelho próximo $(0,78-0,86 \mu \mathrm{m})$ (RODRIGUES et al., 2010; TACHIKAWA et al., 2011).

Os MDEs do instrumento ASTER são denominados de ASTER GDEM (Global Digital Elevation Model), são disponibilizados gratuitamente e com recobrimento aproximadamente global (99\%). Uma das diferenças mais significativas quanto ao SRTM é o fato de o ASTER GDEM não possuir em suas imagens os chamados "voids" (ausência de informações), isso acontece porque seus produtos são obtidos a partir de processo estereoscópico (RODRIGUES et al., 2010).

Estereoscopia é o processo que se ocupa do uso da visão binocular, para a observação de um par de imagens superpostas e posterior projeção que dão à imagem plana a impressão de relevo e com o auxílio de métodos pelos quais essa imagem é produzida em perspectivas diferentes (OLIVEIRA, 1993). O princípio da estereoscopia é explorado na interpretação de imagens, uma vez que as imagens geralmente são obtidas com superposição, permitindo a produção de imagens tridimensionais (ROSA, 2009).

O ASTER GDEM cobre a superfície terrestre entre as latitudes $83^{\circ} \mathrm{N} ; 83^{\circ} \mathrm{S} \mathrm{e}$ é composto por 22.600 cenas. As imagens ASTER GDEM possuem resolução espacial de 1" arco-segundo ( 30m), exatidão de elevação no MDE de $7 \sim 14 \mathrm{~m}$, são distribuídas em imagens no formato GeoTIFF (.tiff), com 16 bits de resolução espectral e referenciadas em coordenadas geográficas lat/long e datum WGS 1984/EGM96. Atualmente estão disponíveis para download no Earth Explorer (USGS) e no site ASTER GEM mantido pela JSPACESUYSTEM. As imagens dispõem de 3601 x 3601 pixel, em $1^{\circ}$ por $1^{\circ}$ (GDEM, 2015; TACHIKAWA et al., 2011). Porém, as imagens 
ASTER são imagens ópticas e não de RADAR como o SRTM, então esta pode ser uma desvantagem, podendo haver algumas falhas de correlação causadas por coberturas de nuvens nas imagens de entrada (RODRIGUES et al., 2010).

\section{Materiais e Métodos}

Para a realização deste trabalho seguiu-se o seguinte roteiro: (a) Levantamento de bibliografia relacionada à temática e suas aplicações; (b) Aquisição de dados raster (SRTM - banda C e banda X -, ASTER GDEM, TOPODATA); (c) Delimitação da BHCR; (d) Relacionamento dos dados; (e) Estatística descritiva; (f) Aplicação do Teste de Comparação Múltipla (Tukey); (g) Análise e discussão dos resultados.

\section{Aquisição de Dados Raster}

Inicialmente foi feita a aquisição das cenas dos instrumentos que se pretendia analisar/comparar, sendo SRTM-C, SRTM-X, ASTER GDEM e TOPODATA.

Por se tratar de uma comparação de dados topográficos, foram relacionadas informações (principalmente os valores altimétricos), provindas de cada instrumento. Assim, as aquisições das imagens dos diferentes instrumentos foram feitas em quatro etapas distintas.

Na primeira foi feita a aquisição dos dados SRTM, banda C (1 cena), com resolução espacial de 90 m, disponibilizados pelo Consortium for Spatial Information (CGIAR-CSI), no endereço eletrônico <http://srtm.csi.cgiar.org/>.

A segunda etapa constou na aquisição de dados Topodata, com resolução de 30 metros (1 cena), a partir de uma interpolação das imagens SRTM (banda C). Os dados Topodata são disponibilizados pelo Banco de Dados Geomorfométricos do Brasil, disponíveis no endereço eletrônico <http://www.dsr.inpe.br/topodata/> (VALERIANO, 2005; VALERIANO et al., 2009).

A terceira etapa constou na aquisição das imagens ASTER de $30 \mathrm{~m}$ de resolução espacial (2 cenas), disponíveis no endereço eletrônico $<$ http://gdem.ersdac.jspacesystems.or.jp/>.

E por último, foram adquiridas imagens SRTM, banda X de $30 \mathrm{~m}$ de resolução espacial ( 2 cenas), disponibilizadas pelo Earth Explorer (USGS), com resolução espacial de $30 \mathrm{~m}$ e disponíveis no endereço eletrônico <http://earthexplorer.usgs.gov/>.

No quadro abaixo são apresentadas as principais características de cada instrumento utilizado para a comparação da diferença dos valores altimétricos (quadro $01)$. 
Quadro 01. Principais características dos instrumentos comparados.

\begin{tabular}{|c|c|c|c|c|}
\hline \multirow{2}{*}{ Característica } & \multicolumn{4}{|c|}{ Instrumento } \\
\hline & SRTM-C & SRTM-X & TOPODATA & ASTER GDEM \\
\hline Data de lançamento & 11 a $22 / 02 / 2000$ & 11 a $22 / 02 / 2000$ & $08 / 2008$ & $29 / 06 / 2009$ \\
\hline Resolução espacial & $90 \mathrm{~m}$ & $30 \mathrm{~m}$ & $30 \mathrm{~m}$ & $30 \mathrm{~m}$ \\
\hline Resolução vertical & $1 \mathrm{~m}$ & $1 \mathrm{~m}$ & $1 \mathrm{~m}$ & $10 \mathrm{~m}$ \\
\hline Acurácia horizontal & $20 \mathrm{~m}$ & * & * & $30 \mathrm{~m}$ \\
\hline Acurácia vertical & $16 \mathrm{~m}$ & $6 \mathrm{~m}$ & * & $12 \mathrm{~m}$ \\
\hline Frequência & $\begin{array}{c}5 \mathrm{GHz} \text { ou } \lambda=5.7 \\
\mathrm{~cm}\end{array}$ & $\begin{array}{c}9 \mathrm{GHz} \text { ou } \lambda=3.2 \\
\mathrm{~cm}\end{array}$ & $\begin{array}{c}5 \mathrm{GHz} \text { ou } \lambda=5.7 \\
\mathrm{~cm}\end{array}$ & $\begin{array}{l}\text { Bandas 3N } \\
\text { (nadir) e 3B } \\
\text { (backward). } \\
0,78-0,86 \mu \mathrm{m}\end{array}$ \\
\hline Tamanho da cena & $225 \mathrm{~km} \times 225 \mathrm{~km}$ & $\sim 50 \mathrm{~km} \times 50 \mathrm{~km}$ & $\begin{array}{l}1^{\circ} \text { lat. por } 1,5^{\circ} \mathrm{de} \\
\text { long. }\end{array}$ & $60 \mathrm{~km} \times 60 \mathrm{~km}$ \\
\hline Projeção & $\begin{array}{c}\text { Coordenadas } \\
\text { Geográficas } \\
\text { (WGS84) }\end{array}$ & $\begin{array}{c}\text { Coordenadas } \\
\text { Geográficas } \\
\text { (WGS84) }\end{array}$ & $\begin{array}{c}\text { Coordenadas } \\
\text { Geográficas } \\
\text { (WGS84) }\end{array}$ & $\begin{array}{c}\text { Coordenadas } \\
\text { Geográficas } \\
\text { (WGS84) }\end{array}$ \\
\hline Formato de dados & 16bits & 16bits & $\begin{array}{c}\text { Codificados em } \\
\text { 32bits } \\
\end{array}$ & 16bits \\
\hline Técnica & Interferometria & Interferometria & $\begin{array}{c}\text { Interpolação a } \\
\text { partir da SRTM-C }\end{array}$ & Estereoscopia \\
\hline
\end{tabular}

*Informações não encontradas ou informadas

\section{Processamento dos Dados Raster}

O processamento das imagens dos instrumentos SRTM, Topodata e ASTER, foi realizado no SIG Global Mapper 16. Neste SIG foram constituídos os mosaicos das imagens SRTM-X e ASTER GDEM, que por suas resoluções espaciais nativas serem menores que SRTM-C e Topodata, influenciam no tamanho de suas cenas, demandando para a esta região a elaboração do mosaico entre duas cenas. Também em ambiente do Global Mapper são gerados os MDEs (imagens de relevo sombreado), hipsometria e curvas de nível para a comparação visual entre as diferentes imagens.

\section{Análise e Diferença dos Dados Topográficos}

A análise estatística de qualquer resultado pretendido em um determinado estudo é uma ferramenta de extrema importância na validação desses dados, assim como para a adequada extrapolação dos resultados obtidos para o conjunto estudado (NORMANDO et al., 2010).

Para a comparação múltipla dos dados altimétricos foi utilizada a análise de variância (ANOVA), uma técnica estatística que permite avaliar afirmações sobre as médias de conjuntos. 
Para esta verificação a ANOVA compara médias de diferentes conjuntos para verificar se estes possuem médias iguais ou não, permitindo que vários grupos sejam comparados a um só tempo. Esta análise de variância representa uma extensão conceitual do teste $t$ para a diferença das médias. É possível utilizar a ANOVA quando se pretende decidir se as diferenças amostrais observadas são reais - causadas por diferenças significativas nos conjuntos observados - ou casuais - decorrentes de mera variabilidade amostral (ROGERSON, 2012).

Para a análise de variância foi utilizado o teste de Tukey para a comparação múltipla dos valores altimétricos e suas diferenças amostrais. Para a obtenção dos valores altimétricos para aplicação do teste de Tukey, inicialmente foi espacializado um grid de pontos virtuais ao longo da área da bacia hidrográfica. Isso porque trataremos os pontos (com os valores altimétricos) como variáveis contínuas, ou seja, distribuídas igualmente ao longo da bacia hidrográfica. A distribuição espacial dos pontos possui distâncias iguais de $1 \mathrm{~km}$ entre os mesmos e um total de 32 pontos, dentro dos limites da bacia hidrográfica do córrego Ribeirãozinho. A espacialização dos pontos ao longo da bacia hidrográfica foi de grande importância pois os padrões espaciais e a dependência espacial dos dados a serem analisados são determinantes na análise geoespacial, onde se estabelecem as informações de atributo (altimetria) de cada ponto, em uma determinada localização espacial.

A matriz com os dados altimétricos foi organizada em forma de tabela utilizando o software Excel. Para a aplicação do teste de comparação múltipla dos dados (Tukey) utilizou-se o software de estatística Action, integrado ao Excel.

Este teste é exato e consiste, então, na comparação de famílias, onde duas a duas, a taxa de erro da família dos testes (FWER) é exatamente $\alpha$ (e o intervalo de confiança é exatamente 1- $\alpha$ (ACTION, 2015).

Métodos de comparações múltiplas exatos são raros. O teste de Tukey tem sido mostrado analiticamente ótimo, no sentido que, entre todos os procedimentos que resultam em intervalos de confiança com mesmo tamanho para todas diferenças duas a duas com coeficiente de confiança da família de pelo menos 1- $\alpha$, o teste de Tukey resulta em intervalos menores. Isso quer dizer que, se a família consiste em todas comparações duas a duas e o teste de Tukey pode ser usado, ele resultará em intervalos menores que qualquer outro método de comparação múltipla de uma etapa (ACTION, 2015, on-line).

A estratégia de Tukey consiste em definir a menor diferença significativa. Tal procedimento utiliza a amplitude da distribuição studentizada (ACTION, 2015), conforme a equação 01 :

$$
C=\frac{1}{2} k(k-1)
$$


Os valores altimétricos foram transferidos para cada ponto de maneira automática a partir da ferramenta Extract by Points, disponível na toolbox Spatial Analyst do ArcMap 10.2.

Todas as imagens estão referenciadas em coordenadas geográficas e datum WGS 1984 e a extração de pontos foi realizada nas imagens com o mesmo referenciamento, para evitar distorções dos valores altimétricos nos mesmos pontos. Outra preocupação na extração dos valores altimétricos, foi manter as cenas inteiras, sem recortes, assegurando que não houvesse a possibilidade do SIG reamostrar automaticamente (por algoritmos nativos) alguns pixels e seus valores, comprometendo a análise.

\section{Resultados}

\section{Comparação Visual}

A primeira comparação a ser feita nos dados foi uma comparação visual entre imagens, o MDE (Relevo Sombreado) e as curvas de nível, com equidistância de $20 \mathrm{~m}$ (figura 03; figura 04; figura 05).

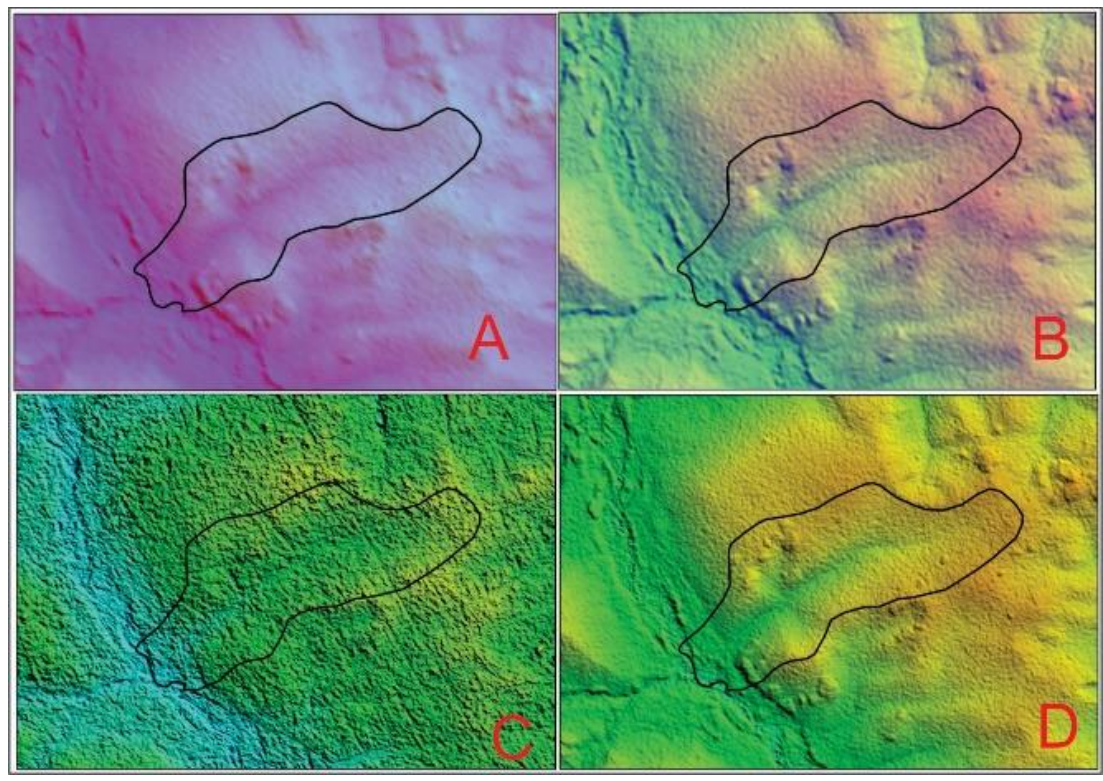

Figura 03. Comparação visual dos MDEs (Relevo Sombreado): a) SRTM-C; b) TOPODATA; c) ASTER GDEM; d) SRTM-X (1:100.000). 


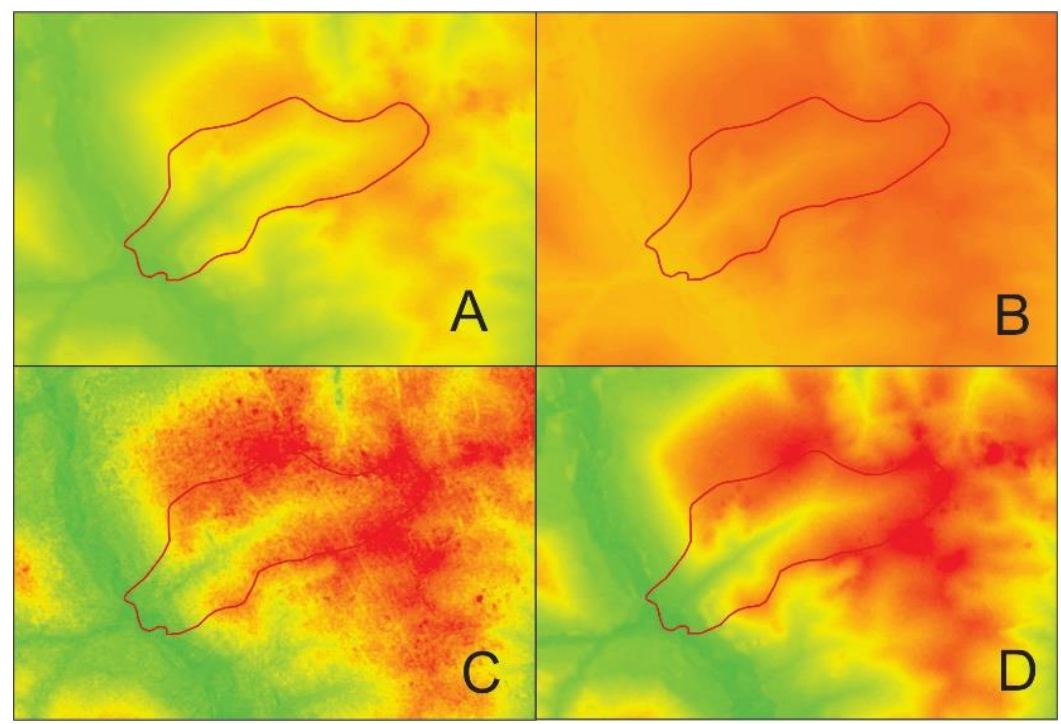

Figura 04. Comparação visual da hipsometria: a) SRTM-C; b) TOPODATA; c) ASTER GDEM; d) SRTM-X (1:100.000).

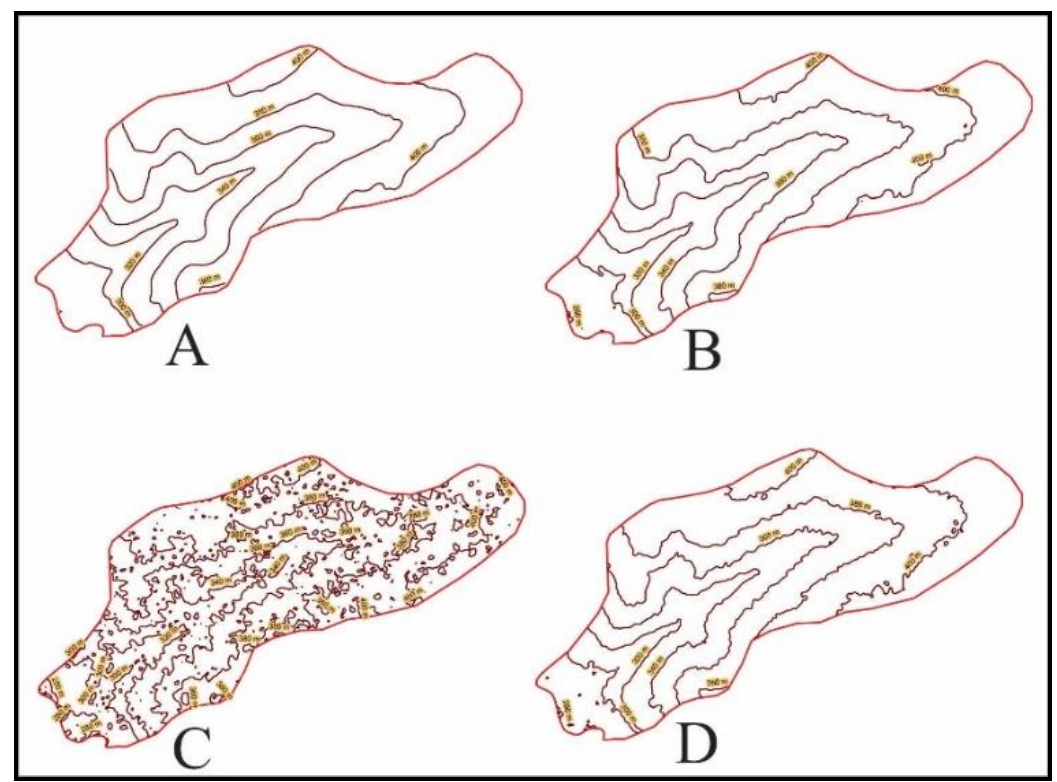

Figura 05. Comparação visual das curvas de nível: a) SRTM-C; b) TOPODATA; c) ASTER GDEM; d) SRTM-X (1:60.000). 
Ao comparar visualmente as quatro imagens dos MDEs, o melhor resultado obtido foi proveniente da imagem SRTM-X. Visualmente, a quantidade de ruídos na referida imagem foi menor, houve melhor definição das feições morfológicas e o histograma de cor foi melhor delimitado, quando comparamos esta imagem com a imagem ASTER GDEM.

Cabe ressaltar, que a análise visual possui um peso do intérprete, que se traduz na opinião individual de cada usuário/gestor, e não deve ser conclusiva para uma comparação. Desta forma, se faz necessária a comparação a partir de testes estatísticos a fim de buscar a acurácia do estudo.

\section{Análise Estatística}

O grid dos 32 pontos apresentou valores altimétricos conforme a figura 06 e a tabela 01 .

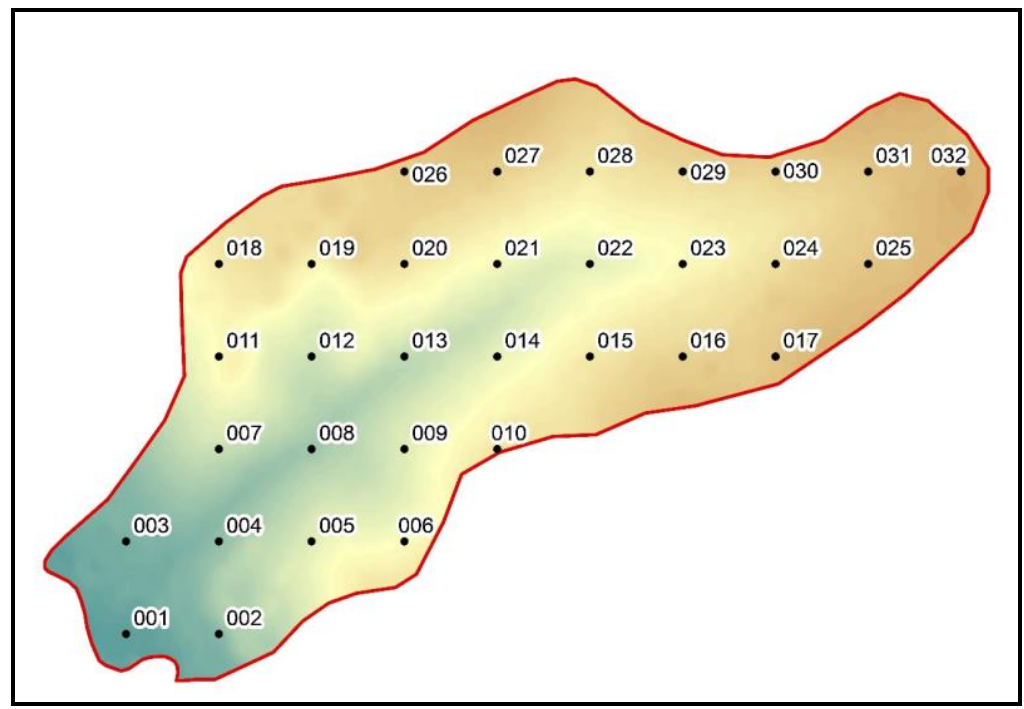

Figura 06. Espacialização do grid de pontos para extração da altimetría.

Tabela 01. Valores altimétricos extraído do grid de pontos amostrais.

\begin{tabular}{c|c|c|c|c}
\hline Pontos & $\begin{array}{c}\text { SRTM-C (Alt. } \\
\text { Metros) }\end{array}$ & $\begin{array}{c}\text { TOPODATA (Alt. } \\
\text { Metros) }\end{array}$ & $\begin{array}{c}\text { ASTER GDEM } \\
\text { (Alt. Metros) }\end{array}$ & $\begin{array}{c}\text { SRTM-X (AIt. } \\
\text { Metros) }\end{array}$ \\
\hline 1 & 281 & 281 & 275 & 281 \\
\hline 2 & 302 & 304 & 295 & 307 \\
\hline 3 & 297 & 296 & 291 & 297 \\
\hline 4 & 310 & 311 & 306 & 312 \\
\hline 5 & 354 & 353 & 346 & 355 \\
\hline 6 & 367 & 368 & 366 & 367 \\
\hline
\end{tabular}




\begin{tabular}{c|c|c|c|c}
\hline Pontos & $\begin{array}{c}\text { SRTM-C (AIt. } \\
\text { Metros) }\end{array}$ & $\begin{array}{c}\text { TOPODATA (AIt. } \\
\text { Metros) }\end{array}$ & $\begin{array}{c}\text { ASTER GDEM } \\
\text { (Alt. Metros) }\end{array}$ & $\begin{array}{c}\text { SRTM-X (AIt. } \\
\text { Metros) }\end{array}$ \\
\hline 7 & 341 & 340 & 326 & 341 \\
\hline 8 & 317 & 316 & 316 & 317 \\
\hline 9 & 351 & 351 & 349 & 353 \\
\hline 10 & 383 & 383 & 387 & 384 \\
\hline 11 & 372 & 370 & 373 & 369 \\
\hline 12 & 344 & 342 & 323 & 343 \\
\hline 13 & 339 & 337 & 336 & 337 \\
\hline 14 & 357 & 358 & 352 & 358 \\
\hline 15 & 383 & 381 & 381 & 381 \\
\hline 16 & 397 & 395 & 385 & 397 \\
\hline 17 & 404 & 403 & 403 & 303 \\
\hline 18 & 381 & 379 & 381 & 373 \\
\hline 19 & 375 & 373 & 370 & 383 \\
\hline 20 & 382 & 383 & 379 & 364 \\
\hline 21 & 363 & 365 & 356 & 354 \\
\hline 22 & 356 & 355 & 349 & 370 \\
\hline 23 & 371 & 370 & 361 & 387 \\
\hline 24 & 388 & 387 & 381 & 404 \\
\hline 25 & 404 & 404 & 400 & 398 \\
\hline 26 & 399 & 398 & 401 & 398 \\
\hline 27 & 397 & 397 & 390 & 381 \\
\hline 28 & 381 & 381 & 377 & 391 \\
\hline 29 & 391 & 391 & 383 & 395 \\
\hline 30 & 396 & 395 & 387 & 403 \\
\hline 31 & 403 & 402 & 396 & 414 \\
\hline 32 & 413 & 413 & 409 & \\
\hline & & & & \\
\hline
\end{tabular}

Ao se comparar a diferença entre os pontos de cada instrumento temos a seguinte organização (tabela 02 ):

Tabela 02. Diferença $(\mathrm{m})$ dos valores altimétricos entre cada instrumento.

\begin{tabular}{c|c|c|c|c|c}
\hline Pontos & $\begin{array}{c}\text { SRTM C- } \\
\text { Topodata }\end{array}$ & $\begin{array}{c}\text { SRTM C- } \\
\text { ASTER }\end{array}$ & $\begin{array}{c}\text { SRTM C- } \\
\text { SRTM X }\end{array}$ & $\begin{array}{c}\text { TOPODATA- } \\
\text { ASTER } \\
\text { GDEM }\end{array}$ & $\begin{array}{c}\text { TOPODATA- } \\
\text { SRTM X }\end{array}$ \\
\hline 1 & 0 & 6 & 0 & 6 & 0 \\
\hline 2 & -2 & 7 & -5 & 9 & -3 \\
\hline 3 & 1 & 6 & 0 & 5 & -1 \\
\hline 4 & -1 & 4 & -2 & 5 & -1 \\
\hline 5 & 1 & 8 & -1 & 7 & -2 \\
\hline 6 & -1 & 1 & 0 & 2 & 1 \\
\hline 7 & 1 & 15 & 0 & 14 & -1 \\
\hline 8 & 1 & 1 & 0 & 0 & -1 \\
\hline 9 & 0 & 2 & -2 & 2 & -2 \\
\hline 10 & 0 & -4 & -1 & -4 & -1 \\
\hline 11 & 2 & -1 & 3 & -3 & 1 \\
\hline 12 & 2 & 21 & 1 & 19 & -1 \\
\hline 13 & 2 & 3 & 2 & 1 & 0 \\
\hline 14 & -1 & 5 & -1 & 6 & 0 \\
\hline 15 & 2 & 2 & 2 & 0 & 0 \\
\hline
\end{tabular}




\begin{tabular}{c|c|c|c|c|c} 
Pontos & $\begin{array}{c}\text { SRTM C- } \\
\text { Topodata }\end{array}$ & $\begin{array}{c}\text { SRTM C- } \\
\text { ASTER }\end{array}$ & $\begin{array}{c}\text { SRTM C- } \\
\text { SRTM X }\end{array}$ & $\begin{array}{c}\text { TOPODATA- } \\
\text { ASTER } \\
\text { GDEM }\end{array}$ & $\begin{array}{c}\text { TOPODATA- } \\
\text { SRTM X }\end{array}$ \\
\hline 16 & 2 & 12 & 0 & 10 & -2 \\
\hline 17 & 1 & 1 & 1 & 0 & 0 \\
\hline 18 & 2 & 0 & 3 & -2 & 1 \\
\hline 19 & 2 & 5 & 2 & 3 & 0 \\
\hline 20 & -1 & 3 & -1 & 4 & 0 \\
\hline 21 & -2 & 7 & -1 & 9 & 1 \\
\hline 22 & 1 & 7 & 2 & 6 & 1 \\
\hline 23 & 1 & 10 & 1 & 9 & 0 \\
\hline 24 & 1 & 7 & 1 & 6 & 0 \\
\hline 25 & 0 & 4 & 0 & 4 & 0 \\
\hline 26 & 1 & -2 & 1 & -3 & -1 \\
\hline 27 & 0 & 7 & -1 & 7 & 0 \\
\hline 28 & 0 & 4 & 0 & 4 & 0 \\
\hline 29 & 0 & 8 & 0 & 8 & -1 \\
\hline 30 & 1 & 9 & 1 & 8 & -1 \\
\hline 31 & 1 & 7 & 0 & 6 & \\
\hline 32 & 0 & 4 & -1 & 4 & \\
\hline
\end{tabular}

Os valores altimétricos apresentaram as seguintes variações (tabela 3):

Tabela 03. Estatística descritiva da altimetria extraída de cada instrumento.

\begin{tabular}{c|c|c|c|c|c}
\hline Instrumento & Média & Valor Máximo & Valor Mínimo & Mediana & Desvio Padrão \\
\hline $\begin{array}{c}\text { SRTM } \\
\text { banda C) }\end{array}$ & 365,59375 & 413 & 281 & 373,5 & 33,9686 \\
\hline TOPODATA & 365,0625 & 413 & 281 & 371,5 & 33,76012 \\
\hline $\begin{array}{c}\text { ASTER } \\
\text { GDEM }\end{array}$ & 360,3125 & 409 & 275 & 371,5 & 35,04322 \\
\hline $\begin{array}{c}\text { SRTM } \\
\text { (banda X) }\end{array}$ & 365,46875 & 414 & 281 & 371,5 & 33,5205 \\
\hline
\end{tabular}

Analisando a estatística descritiva dos dados, percebemos que existe uma diferença, mesmo que moderada, entre os instrumentos. Nesta diferença, a que mais chama atenção é a ASTER GDEM, a única apresentada com média da altimetria de $360 \mathrm{~m}$ ( $5 \mathrm{~m}$ a menos em relação aos outros instrumentos), com $6 \mathrm{~m}$ de valor mínimo, divergente aos outros instrumentos e com o maior desvio padrão, apresentado em 35, contra 33 de todos os outros instrumentos.

Para buscar considerações quanto a diferença estatisticamente comprovada entre valores extraídos, aplicamos o teste de Tukey para fazer comparação e correlação dos valores, para que fosse possível concluir a partir de estatística quais foram as maiores diferenças e/ou semelhanças entre os valores de cada instrumento. Ao aplicar o teste de Tukey, chegamos aos seguintes dados do processo (tabela 04; figura 07). 
Tabela 04: Teste de Tukey dos dados analisados.

\begin{tabular}{c|c|c|c|c}
\hline Níveis & Centro & Limite Inferior & Limite Superior & P-valor \\
\hline TOPODATA-SRTM C & $-0,53125$ & $-23,07290484$ & 22,01040484 & 0,999916582 \\
\hline ASTER GDEM-SRTM C & $-5,28125$ & $-27,82290484$ & 17,26040484 & 0,928691715 \\
\hline SRTM X-SRTM C & $-0,125$ & $-22,66665484$ & 22,41665484 & 0,999998912 \\
\hline ASTER GDEM-TOPODATA & $-4,75$ & $-27,29165484$ & 17,79165484 & 0,9467257 \\
\hline SRTM X-TOPODATA & 0,40625 & $-22,13540484$ & 22,94790484 & 0,999962675 \\
\hline SRTM X-ASTER GDEM & 5,15625 & $-17,38540484$ & 27,69790484 & 0,933205302 \\
\hline
\end{tabular}

O teste de Tukey avalia a igualdade entre os níveis, então é um teste de hipóteses (ACTION, 2015). Para a avaliação da hipótese dos dados altiméticos utilizouse uma taxa de erro para os conjuntos do teste em 0,05 determinada no campo Alfa (FWER). Foi a partir desta taxa de erro que o teste de Tukey determinou quais valores altimétricos são estatisticamente próximos dentre os instrumentos comparados. Em geral, na análise dos dados do processo todos os valores de $P$ se apresentaram acima de 0,05 (valor para taxa de erro escolhida), ou seja, a significância do resultado das análises se mostrou verdadeira. Isso ocorreu devido ao valor $P$ (menor nível de significância) obtido estar acima de 0,05 . Observa-se a partir disso que o resultado obtido para o estudo é estatisticamente significante. Do contrário, tem-se a mesma situação para o coeficiente de correlação entre os níveis de comparação, sendo que os resultados da correlação se apresentaram acima de 0,90 , indicando uma paridade dos valores altimétricos entre os sensores comparados.

Desta maneira, vemos que a hipótese de diferença dos valores altimétricos é estatisticamente rejeitada a partir da aplicação do teste de Tukey na área amostral da bacia hidrográfica do córrego Ribeirãozinho. Ou seja, todos os $P$-valor $>0,05$.

Então, com o resultado da aplicação do teste de Tukey, provou-se que estatisticamente os valores altimétricos dos instrumentos usados para a comparação são próximos e possuem uma grande similaridade de altitude nos pontos amostrados.

Entretanto, é possível a partir do teste de Tukey identificar quais instrumentos dentre os quatro comparados possuem a maior similaridade (mesmo estatisticamente sendo iguais, o gráfico de intervalo de confiança nos mostra uma pequena discrepância entre os instrumentos) quanto aos valores de altimetria do terreno.

Os instrumentos SRTM-C e SRTM-X são os que possuem a maior paridade nos pontos amostrados, seguida pela comparação SRTM-X e Topodata. Em contrapartida a maior disparidade entre instrumentos ocorreu na comparação entre ASTER GDEM e SRTM-C (figura 07). 


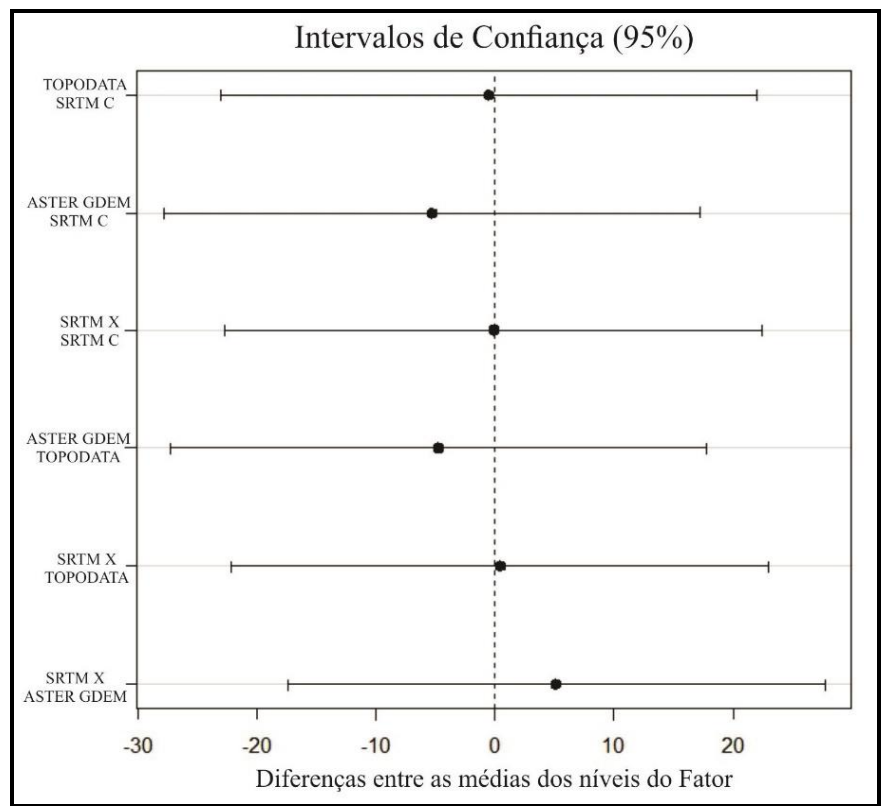

Figura 07. Espacialização do grid de pontos para extração da altimetría.

A maior similaridade entre os dados da SRTM-C e SRTM-X acontece devido ao desenvolvimento e características dos instrumentos. Como explicado anteriormente, os dados destes instrumentos foram coletados nas mesmas condições e num mesmo sobrevoo, diferenciados apenas pela antena, um possível processamento (laboratórios e centro de distribuição diferentes) e resolução espacial. É possível que a principal diferença altimétrica nas cenas destes instrumentos seja pela diferença da resolução espacial. Para a comparação de maior disparidade (ASTER GDEM e SRTM-C) uma possível justificativa seria por conta, primeiramente da resolução espacial e pelo processo de constituição da cena, sendo a SRTM-C imagens de radar constituídas a partir de interferometria e as ASTER GDEM imagens ópticas constituídas a partir de estereoscopia.

A escolha das imagens e consequentemente do instrumento a ser usado vai variar de acordo com o interesse usuário. Corroborando com as considerações de Fuckner et al. (2009) e Fuckner e Silva-Junior (2010) os autores ressaltam que a interferometria pode levar a melhores resultados do que a estereoscopia. À época, apesar favorecerem a SRTM devido a interferometria em seu processo de formação, eles lembravam que, por outro lado, viam vantagem nos dados ASTER GDEM por este apresentar maior resolução espacial.

A partir da data de lançamento do sensor ASTER, na época seus produtos se tornaram uma alternativa ao uso de dados SRTM, já que possuem uma resolução 
espacial de $30 \mathrm{~m}$ e, dados obtidos através de estereoscopia, tendo um resultado final diferenciado, se comparado ao SRTM e Topodata (ANDRADES-FILHO, 2009 apud MARQUES et al., 2011).

No entanto, Rosa (2009) explica que uma das vantagens de dados de RADAR (SRTM) sobre dados ópticos (ASTER GDEM) é que o RADAR por ser um sensor ativo pode operar à noite, porém a vantagem mais importante é a de poder ser operado praticamente sob qualquer condição atmosférica.

A grande vantagem relacionada aos dados SRTM-X, assim como nos dados derivados da banda $\mathrm{C}$, está no fato terem sido derivados de interferometria, ou seja, não sofrem interferência significativa de parâmetros atmosféricos. O que vem a ser uma vantagem em relação aos dados gerados por estereoscopia ótica (o caso do ASTER GDEM), já que um dos problemas do ASTER GDEM é que a cobertura de nuvens e aerossóis podem causar interferência nos modelos. Entretanto, os dados gerados a partir da banda X, possuem relativamente mais "buracos" na cobertura, sendo isso uma consequência de sua alta resolução espacial demandada (SADECK, 2013).

Em contraponto, Schunemann e Novacovski (2011) ao avaliarem (visualmente) modelos 3D gerados a partir de imagens ASTER GDEM e SRTM (banda C) dão preferência à utilização de imagens ASTER GDEM, pois, segundo os autores, pelo motivo da imagem altimétrica ASTER GDEM ser resultante de levantamento de pares estereoscópicos de imagens, ela fornece o modelo de elevação da superfície e não propriamente do terreno, ou seja, os erros encontrados (ruídos) na altimetria são derivados de feições tanto acima quanto abaixo do terreno, como vegetação, desníveis no terreno, edificações, entre outras. Ainda no trabalho desenvolvido por eles a opção da utilização dos produtos ASTER GDEM, para modelo de superfície, está em vantagem quanto aos produtos SRTM (modelo de elevação), mesmo com os ruídos apresentados, podendo ser utilizados em escalas maiores desde que sejam aliados a outras feições de apoio, como pontos cotados, hidrografia, entre outros, e ajustadas e corrigidas imperfeições visualmente localizadas, o que torna importante o apoio de profissionais que realizem levantamentos em campo (MARCUZZO e CARDOSO, 2013)

Biffi et al. (2013) ao compararem MDEs gerados a partir de SRTM-C e ASTER GDEM em relação à precisão quanto a elevação de edificações específicas, consideram que visualmente a superfície gerada que mais se aproximou da superfície de comparação da prefeitura municipal de Lages/SC foi o SRTM-C. E, apesar do ASTER possuir uma melhor resolução espacial em relação ao SRTM-C, a superfície gerada por ele mostra-se visualmente suavizada. Porém os autores admitem que uma análise visual não é conclusiva para uma comparação.

Ao analisar também os valores altimétricos, os mesmos autores confirmaram uma maior aproximação dos valores SRTM-C com a base da prefeitura em relação à comparação dos valores ASTER com a mesma base da prefeitura para os pontos amostrados. Mostrando assim que os dados SRTM possuem um erro altimétrico menor comparado com ASTER na área analisada. E concluíram que o MDE do SRTM possui 
valores mais próximos aos dados da base cartográfica da prefeitura do município de Lages, em relação aos valores do MDE do ASTER.

Sadeck (2013) ao fazer uma análise visual entre SRTM-C, SRTM-X e TOPODATA, notou a grande frequência de erros na área do rio, porém, ele afirma que os mesmos podem ser corrigidos a partir de operações em SIG. Segundo o autor, dois pontos essenciais devem ser elucidados para aqueles que pretendem utilizar MDEs da SRTM-X. O primeiro é verificar a disponibilidade para a área de trabalho. E o segundo é a correção dos erros (picos e vórtices) da imagem que resultam em valores de elevação irreais.

\section{Considerações Finais}

A primeira consideração é acerca do resultado dos $\mathrm{P}$-valores $>0,05$. Isto prova que a hipótese de desigualdade entre os valores altimétricos é rejeitada estatisticamente a partir do Teste de Tukey. Mesmo assim, num segundo momento, o gráfico com os intervalos de confiança aponta a maior semelhança entre os valores são da comparação entre os instrumentos SRTM-C e SRTM-X e maior disparidade entre SRTM-C e ASTER GDEM. Porém é importante reafirmar que o teste de comparação nos mostra que estatisticamente os valores altimétricos não possuem diferença.

Ao concluir que os valores estatisticamente não são desiguais, não significa afirmar que as médias sejam iguais, ou que os valores são inflexivelmente os mesmos para cada amostra. Com o teste não acusando desigualdade entre os dados analisados, temos apenas uma indicação que não houve evidência suficientemente forte para provar que essas diferenças são significativas numericamente.

Especificamente neste trabalho, concluímos que a melhor escolha seria optar pela SRTM-X, devido sua resolução espacial, representação do terreno, comparação visual das curvas de nível e seu processo de criação (interferométrico), a partir de uma comparação visual entre os produtos de cada instrumento aqui avaliado.

Ao revisar a bibliografia disponível com estudos comparativos de MDEs foi verificado que ao afirmar o melhor produto à cada trabalho, os autores refletem opiniões próprias, que variam de acordo com as necessidades locais de cada trabalho. A quase unanimidade ficam por conta de dados SRTM (principalmente banda C), até por conta destes dados serem os primeiros a terem distribuição gratuita e cobertura global.

Quanto às comparações visuais e a estatística descritiva dos instrumentos, concluímos a pertinência quanto à similaridade entre SRTM-C e SRTM-X, e a maior diferença entre ASTER GDEM e SRTM-C. Acredita-se que a maior diferença ocorreu devido ao processo de constituição do MDE e principalmente pela resolução espacial de cada instrumento.

Para posteriores trabalhos, recomenda-se a realização de diferentes testes, para diferentes regiões. Cabe ressaltar ademais, que, os resultados (e o p-valor) podem ser influenciados pela quantidade de amostras, que em outros estudos pode/deve ser 
diversificada da quantidade aqui utilizada. O presente trabalho serviu para direcionar os procedimentos metodológicos para futuros estudos analíticos desta natureza e contribuir para nortear novos caminhos de exploração de valores altimétricos de MDEs, para regiões com características diferentes.

\section{Agradecimentos}

O primeiro autor agradece ao Programa de Pós-Graduação em Geografia (PPGGEO) da Universidade Federal de Mato Grosso do Sul e à CAPES pela bolsa concedida.

\section{Referências Bibliográficas}

ACTION. Teste de Tukey (TSD - Tukey Significant Difference). Portal Action. Disponível em: $<$ http://www.portalaction.com.br/anova/31-teste-de-tukey>. Acesso em: 25 jul. 2015.

BERGAMO, E. de P; ALMEIDA, J. A. P. de. A Importância da Geomorfologia para o Planejamento Ambiental: Um Estudo do Município de Fartura/SP. In: VI SINAGEO IV Simpósio Nacional de Geomorfologia e I.A.G. Regional Conference on Geomorphology: Geomorfologia Tropical e Subtropical: Processos, Métodos e Técnicas, 2006, Goiania, GO. Anais... Goiânia, GO: SINAGEO, 2006. v. 1.

BIFFI, L. J.; JARENKOW, G. L; FRANCHINI, R. L.; VIEIRA, R. M.; RAFAELINETO, S. L.; CORDEIRO, M. T. A. Comparação de modelos digitais de elevação de SRTM e ASTER com modelo de elevação de grande escala do município de Lages - SC. In: SIMPÓSIO BRASILEIRO DE SENSORIAMENTO REMOTO, 16. (SBSR), 2013, Foz do Iguaçu. Anais... São José dos Campos: INPE, 2013. p. 4647-4652. DVD, Internet. ISBN 978-85-17-00066-9 (Internet), 978-85-17-00065-2 (DVD). Disponível em: $<$ http://marte2.sid.inpe.br/rep/dpi.inpe.br/marte2/2013/05.29.00.46.33>. Acesso em: 26 jul. 2015.

BRAZ, A. M.; MIRANDOLA, P. H. Geotecnologias Aplicada: uma análise ambiental da bacia hidrográfica do córrego carro queimado. 1. ed. Saarbrücken: Novas Edições Acadêmicas, 2015. 145 p.

FUCKNER, M. A. et al. Avaliação altimétrica de modelos digitais de elevação extraídos de imagens ASTER em áreas com configuração topográfica distinta. In: SIMPÓSIO BRASILEIRO DE SENSORIAMENTO REMOTO, 14. (SBSR), 2009, Natal. Anais... São José dos Campos: INPE, 2009. p. 683-690. DVD, On-line. ISBN 978-85-17-000447. (INPE-15962-PRE/10571). Disponível em: $<$ http://marte.sid.inpe.br/col/dpi.inpe.br/sbsr\%4080/2008/11.17.21.49/doc/683-690.pdf>. Acesso em: 25 jul. 2015. 
FUCKNER, M. A.; SILVA-JUNIOR, O. M. Avaliação da Correlação entre Modelo Digital de Elevação ASTER e Carta Topográfica para a Região de Marabá - Estado do Pará. In: SIMPÓSIO BRASILEIRO DE CIÊNCIAS GEODÉSICAS E TECNOLOGIAS DA GEOINFORMAÇÃO, 3. (SIMGEO), 2010. Recife. Anais... Recife: UFPE, 2010. p. 000-000. On-line. ISBN: 978-85-63978-00-4. Disponível em: $<$ https://www.ufpe.br/cgtg/SIMGEOIII/IIISIMGEO_CD/artigos/FotoeSR/SR_e_PDI/R_ 248.pdf>. Acesso em: 25 jul. 2015.

Global Digital Elevation Model - GDEM. JSPACESYSTEMS. Features/About "ASTER", an earth observing satellite sensor. Disponível em: $<$ http://www.jspacesystems.or.jp/ersdac/GDEM/E/1.html>. Acesso em: 20 jul. 2015.

IBGE - Instituto Brasileiro de Geografia e Estatística. Manual Técnico de Geomorfologia. 2 ed. Coordenação de Recursos Naturais e Estudos Ambientais. Rio de Janeiro: IBGE, 2009. 182 p. (Manuais Técnicos em Geociências).

IWASHITA, F.; SOUZA-FILHO, C. R. Avaliação da interpolação de dados SRTM-90 $\mathrm{m}$ através de dados SRTM-30 $\mathrm{m}$ do território americano. In: SIMPÓSIO BRASILEIRO DE SENSORIAMENTO REMOTO, 14. (SBSR), 2009, Natal. Anais... São José dos Campos: INPE, 2009. p. 3927-3934. DVD, On-line. ISBN 978-85-17-00044-7. (INPE15962-PRE/10571). Disponível em:

$<$ http://marte.sid.inpe.br/col/dpi.inpe.br/sbsr\%4080/2008/11.16.18.55/doc/39273934.pdf>. Acesso em: 07 fev. 2015.

Jet Propulsion Laboratory - JPL. U. S. Releases Enhanced Shuttle Land Elevation Data. JPL/NASA. Disponível em: <http://www2.jpl.nasa.gov/srtm/index.html >. Acesso em 21 jul. 2015.

MARQUES, H. G.; PENATTI, N. C.; PARANHOS-FILHO, A. C.; FROEHLICH, O.; ALMEIDA, T. I. R.; SHIMABUKURO, Y. Comparação entre os modelos de elevação SRTM, TOPODATA e ASTER na delimitação automática de rede de drenagem e limite de bacia hidrográfica. In: SIMPÓSIO BRASILEIRO DE SENSORIAMENTO REMOTO, 11. (SBSR), 2011, Curitiba. Anais... São José dos Campos: INPE, 2011. p. 1271-1278. DVD, Internet. ISBN 978-85-17-00056-0 (Internet), 978-85-17-00057-7 (DVD). Disponível em: $<$ http://www.dsr.inpe.br/sbsr2011/files/p1263.pdf>. Acesso em: 26 jul. 2015.

NORMANDO, D.; TJÄDERHAE, L.; QUINTÃO, C. C. A. A escolha do teste estatístico - um tutorial em forma de apresentação em PowerPoint. Dental Press J. Orthod. 101 v. 15, no. 1, p. 101-106, Jan./Feb. 2010.

NOVO, E. M. L. M. Sensoriamento Remoto: princípios e aplicações. 4 ed. São Paulo: Blucher, 2010. $387 \mathrm{p}$.

OLIVEIRA, C. Dicionário Cartográfico. $4^{\mathrm{a}}$ ed. Rio de Janeiro: Instituto Brasileiro de Geografia e Estatística (IBGE), 1993. 646 p. 
PRATES, I. Dados SRTM com resolução espacial de 30m são disponibilizados. MundoGEO. Disponível em: $<$ http://mundogeo.com/blog/2014/09/25/dados-srtm-com-resolucao-espacialde-30-m-sao-disponibilizados/>, 25 de setembro de 2014. Acesso em: 22 jul. 2015.

RODRIGUES, T. L.; DEBIASI, P.; SOUZA, R. F. Avaliação da adequação dos produtos ASTER GDEM no auxílio ao mapeamento sistemático brasileiro. In: III Simpósio Brasileiro de Ciências Geodésicas e Tecnologias da Geoinformação - III SIMGEO, 2010, Recife. Anais... Recife, PE: SIMGEO. 27-30 de julho de 2010 p. $001-005$

ROGERSON, P. A. Métodos Estatísticos para Geografia: um guia para o estudante. Tradução técnica: Paulo Fernando Braga Carvalho e José Irineu Rangel Rigotti. $3^{\mathrm{a}}$ ed. Porto Alegre: Bookman, 2012. 348 p.

ROSA, R. Introdução ao Sensoriamento Remoto. 7 ed. Uberlândia: EDUFU, 2009. 264p.

SADECK, L. W. R. Dados SRTM (banda X) com 30 m de resolução espacial disponíveis para o Brasil. SADECK - Geotecnologias. Disponível em:

$<$ https://geotecnologias.wordpress.com/2013/08/06/dados-srtm-banda-X-com-30-m-deresolucao-espacial-disponiveis-para-o-brasil/>, 06 de agosto de 2013. Acesso em: 22 jul. 2015.

SCHUNEMANN, F. F.; NOVACOVSKI, C. Avaliação visual de modelos 3D gerados através de produtos ASTER GDEM, SRTM e carta topográfica em relação a fotos do relevo. In: SIMPÓSIO BRASILEIRO DE SENSORIAMENTO REMOTO, 11. (SBSR), 2011, Curitiba. Anais... São José dos Campos: INPE, 2011. p. 5737-5744. DVD, Internet. ISBN 978-85-17-00056-0 (Internet), 978-85-17-00057-7 (DVD). Disponível em: <http://marte.sid.inpe.br/col/dpi.inpe.br/marte/2011/07.05.19.13/doc/p1252.pdf>. Acesso em: 26 jul. 2015.

SIMÕES, M. G. Modeladores Digitais de Terreno em Sistema de Informação Geográfica, 1993. 158 f. Dissertação (Mestrado em Engenharia de Sistemas e Computação) - Instituto Alberto Luiz Coimbra de Pós-Graduação e Pesquisa de Engenharia (COPPE), Universidade Federal do Rio de Janeiro (UFRJ), Rio de Janeiro.

SOARES, J. V. Fundamentos de Sensoriamento Remoto por Radar. Conceitos Básicos de Sensores Radar. Curso de Sensores Remotos Radar - INPE, 2005. Disponível em: $<$ http://www.dsr.inpe.br/dsr/vianei/radar/DOCs_PDFs/Livro_Radar.pdf $>$. Acesso em 13 jul. 2015.

SOUZA-FILHO, C. R. O relevo das Américas como nunca antes visto. MundoGEO. Disponível em: <http://mundogeo.com/blog/2003/12/18/o-relevo-das-americas-comonunca-antes-visto/>, 18 de dezembro de 2003. Acesso em: 22 jul. 2015.

TACHIKAWA, T.; HATO, M.; KAKU, M.; IWASAKI, A. Characteristics of ASTER GDEM version 2. International Geoscience and Remote Sensing Symposium (IGARSS), art. no. 6050017, pp. 3657-3660, 2011. 
VALERIANO, M. M. Modelo digital de elevação com dados SRTM disponiveis para a América do Sul. São José dos Campos, SP: INPE: Coordenação de Ensino, Documentação e Programas Especiais (INPE-10550-RPQ/756). 72p., 2004 (Boletim).

VALERIANO, M. M. Modelo digital de variáveis morfométricas com dados SRTM para o território nacional: o projeto TOPODATA. In: SIMPÓSIO BRASILEIRO DE SENSORIAMENTO REMOTO, 12. (SBSR), 2005, Goiânia. Anais... São José dos Campos: INPE, 2005. p. 3595-3602. CD-ROM, On-line. ISBN 85-17-00018-8. (INPE12615-PRE/7908). Disponível em:

$<$ http://marte.sid.inpe.br/col/ltid.inpe.br/sbsr/2004/10.29.11.41/doc/3595.pdf > . Acesso em: 17 jun. 2015.

VALERIANO, M. M. Topodata: guia para utilização de dados geomorfológicos locais. São José dos Campos, SP: INPE: Coordenação de Ensino, Documentação e Programas Especiais (INPE-15318-RPE/818). 72p., 2008 (Boletim).

VALERIANO, M. M. et al. Topodata: desenvolvimento da primeira versão do banco de dados geomorfométricos locais em cobertura nacional. In: Simpósio Brasileiro de Sensoriamento Remoto, 2009, Natal, RN. Anais... São José dos Campos, SP: INPE, 2009. v. CD-ROM. p. 1-8.

VALERIANO, M. M.; ALBUQUERQUE, P. C. G. Topodata: processamento dos dados SRTM. São José dos Campos, SP: INPE: Coordenação de Ensino, Documentação e Programas Especiais (INPE-16702-RPQ/854). 79p., 2010 (Boletim).

VALERIANO, M. M.; ROSSETTI, D. F. Topodata: seleção de coeficientes geoestatísticos para refinamento unificado de dados SRTM. São José dos Campos, SP: NPE: Coordenação de Ensino, Documentação e Programas Especiais (INPE-16701RPQ/853). 74p. 2010 (Boletim).

\section{Adalto Moreira Braz}

Mestre em Geografia pelo Programa de Pós-Graduação em Geografia da Universidade Federal do Mato Grosso do Sul e graduado em Geografia pela Universidade Federal de Mato Grosso do Sul. Atualmente é doutorando em Geografia do Programa de PósGraduação em Geografia pela Universidade Federal de Goiás - Regional Jataí.

Campus Riachuelo. Rua Riachuelo, CP 03. CEP 75804-020 - Jataí, GO - Brasil.

E-mail: adaltobraz.geografia@gmail.com

Fernanda Vieira Xavier

Doutora em Geociências pela Universidade Estadual Paulista, mestre em Física Ambiental pela Universidade Federal de Mato Grosso e graduada em Geografia pela Universidade Federal de Viçosa. Atualmente é Professora Substituta do curso de Geografia da Universidade do Estado de Mato Grosso - Campus de Cáceres. Av. São João, s/n. Cep: 78200-000 - Cáceres, MT - Brasil.

E-mail: ferx.unesp@gmail.com 


\section{Patricia Helena Mirandola Garcia}

Doutora em Geografia pela Universidade Federal do Rio de Janeiro, mestre em Geografia pela Universidade Estadual Paulista e graduada em Geografia pela Faculdade Auxilium de Filosofia, Ciência e Letras. Atualmente é professora do curso de Geografia da Universidade Federal de Mato Grosso do Sul - Campus de Três Lagoas, onde também atua no Programa de Pós-Graduação em Geografia (PPGGEO).

Av. Ranulpho Marques Leal, 3484. Cep: 79620-080 - Três Lagoas, MS - Brasil.

E-mail: patricia.garcia@ufms.br

Recebido para publicação em maio de 2016 Aprovado para publicação em janeiro de 2017 